\title{
中国农业环境效率时空演变及其驱动因素
}

\author{
徐维祥 ${ }^{1}$, 郑金辉 ${ }^{1, *}$, 李续双 ${ }^{2}$ \\ 1 浙江工业大学经济学院, 杭州 310023 \\ 2 浙江大学经济学院, 杭州 310027
}

\begin{abstract}
摘要:农业环境效率是衡量经济与资源环境协调发展的重要指标, 研究农业环境效率对实现农业资源的高效率利用具有重要意 义。基于 2004-2019 年中国 30 个省(市、区) 面板数据,运用 SBM ( Slacks-based model) 模型、空间马尔科夫链、GIS 技术和空间 计量模型, 分析了农业环境效率的时空演变特征, 研究了农业环境效率变动的驱动因素。结果表明: (1)2004一2019 年, 考虑非 期望产出的农业环境效率要低于不考虑非期望产出情况, 呈持续上升趋势; 区域差异整体呈倒“V”型变化趋势, 东西方向上递 减,南北方向上呈 “U” 型趋势特征。(2) 中国不同等级的农业环境效率空间差异明显,地理空间格局在空间演变过程具有重要 作用,空间关联性特征显著,不同类型的演变存在显著的时空惯性。(3) 中国农业环境效率存在空间溢出效应,农业经济水平、 环境规制、农业生产能力是提升农业环境效率的关键因素,财政支农水平、工业化水平、农作物种植结构、农业机械强度则是制 约效率提升的约束要素。
\end{abstract}

关键词 : 农业环境效率;SBM 模型;时空特征;空间杜宾模型

\section{Spatio-temporal evolution and driving factors of agricultural environmental efficiency in China}

\author{
XU Weixiang ${ }^{1}$, ZHENG Jinhui $^{1, *}$,LI Xushuang ${ }^{2}$ \\ 1 School of Economics, Zhejiang University of Technology, Hangzhou 310023, China \\ 2 School of Economics, Zhejiang University, Hangzhou 310027, China
}

\begin{abstract}
The agricultural environmental efficiency which combines both economic and environmental performance is of great significance to the efficient utilization of agricultural resources. Taking 30 provinces ( cities and districts) in China as the research object, this paper used SBM (Slacks-based model) model, spatial Markov chain, GIS technology to depict the spatio-temporal evolution characteristics of agricultural environmental efficiency, then analyzed the influencing factors by using spatial Durbin model. The results showed that: (1) The agricultural environmental efficiency based on the nonexpected output was lower than that without the non-expected output, which presented a continuous upward trend. The regional difference indicated an overall inverted $\mathrm{V}$ trend, the agricultural environmental efficiency decreased in the east-west direction, and the south-north direction showed a U shape pattern. (2) The different levels of the agricultural environmental efficiency had obviously spatial differences and spatial correlation characteristics. The geospatial structure played an important role in the spatio-temporal evolution and the spatial agglomeration was significant, and the evolution of different efficiency types had significant temporal and spatial inertia. (3) The agricultural environment efficiency had spatial spillover effects, the agricultural economic level, the environmental regulation and the agricultural production capacity played significant roles in improving the agricultural environmental efficiency, while the agriculture financial support, the
\end{abstract}

基金项目: 国家社会科学基金重大项目(18ZDA045)

收稿日期:2020-02-18; 网络出版日期:2021-07-05

*通讯作者 Corresponding author.E-mail: 852808422@qq.com 
industrialization level, the crop planting structure and the agricultural machinery strength would inhibit its development.

Key Words : agricultural environmental efficiency; SBM model; spatio-temporal characteristics; spatial Durbin model

改革开放以来,伴随经济的高速增长,中国农业经济取得了巨大成就, 获得了长足发展。但与此同时,在 农业经济附加值快速增长过程中忽视了发展质量,农业生态环境问题日益严重, 如土壤地力破坏、农业面源污 染、要素资源消耗与环境效率低下等问题 ${ }^{[1]}$ 。党的十九大指出, 建设生态文明是中华民族永续发展的千年大 计, 必须树立和践行绿水青山就是金山银山的理念, 并把农业面源污染治理列人着力解决的突出环境问题之 一, 推动农业绿色发展是破解中国农业发展生态环境压力的重要方式, 也是满足人民日益增长的美好生活需 要的客观要求。生态文明建设战略要求下,促进农业经济发展同时降低对生态环境的影响,不断提高经济产 出与环境效应间的协调性,提升环境效率是重要的实现途径。因此,在资源环境约束视角下,分析中国农业环 境效率的时空演变特征及其驱动因素, 对于推动农业生产的生态服务功能具有重要现实意义。

传统经济增长理论没有考虑经济增长与环境污染的关系,生态环境约束下,传统的增长效率测算方法存 在一定缺陷。为此, 学术界提出了生态效率的概念 ${ }^{[2]}$, 后经可持续发展世界经济理事会 (WBCSD) 拓展为环境 效率 $(\mathrm{EE})$ 和资源效率 $(\mathrm{RE})$ 两部分 ${ }^{[3]}$ 。当前生态环境约束下的效率与生产率问题已成为学术界研究的热点, 农业环境效率指以尽可能较小的资源消耗和较低的污染程度, 尽可能增加农业产出, 主要强调农业生产的经 济发展与生态环境的统一。目前, 对农业环境效率研究主要包括以下方面:一是在研究尺度方面,主要集中在 宏观、中观尺度,包括省域 ${ }^{[4]}$ 、市域 ${ }^{[5]}$ 、县域 ${ }^{[6]}$, 也有学者从微观数据尺度进行了研究 ${ }^{[7-8]}$ 。二是在研究方法与 影响因素方面, 学者们常用的测度方法主要有指标体系法 ${ }^{[9]}$ 、生态足迹法 ${ }^{[10]}$ 、随机前沿法 $(\mathrm{SFA})^{[11]}$ 和数据包 络分析法 $(D E A)^{[12]}$; 在分析影响因素时常用多元线性模型 ${ }^{[13]}$ 、Tobit 模型 ${ }^{[1]}$ 、门槛模型 ${ }^{[14]}$ 的方法。三是在研 究内容方面, 早期主要在理论分析 ${ }^{[15]}$ 、效率测度 ${ }^{[16]}$ 及时空演化 ${ }^{[17]}$ 等方面, 目前更加关注农业环境效率的影 响因素及其空间溢出效应 ${ }^{[18]}$,如侯孟阳等运用空间杜宾模型发现财政支农水平对农业环境效率产生显著的 正向空间溢出效应 ${ }^{[19]}$ 。此外, 研究表明工业化水平、农业机械投人、农业生产能力、农业劳动者教育素质等对 农业环境效率产生影响 ${ }^{[20]}$ 。

综上所述, 当前中国农业环境效率的研究,还可以从以下方面进一步深化和拓展: (1) 在研究内容上,主 要集中在指标评价、时空特征等方面的分析,鲜有文献从动态演进角度对农业环境效率空间关联与转移趋势 进行探讨。(2) 在研究方法上,大多采用 SFA、DEA 测度农业环境效率, 无法将同处于有效前沿面的评价单元 进行区分。此外, 过往研究大多采用普通线性回归分析其影响因素, 忽视了地区间的空间关联性。鉴于此, 本 文基于非期望产出视角,采用 SBM 模型,综合测度 2004-2019 年中国 30 个省(市、区) 的农业环境效率,并利 用 GIS 技术和空间马尔科夫链刻画农业环境效率的时空演变特征,在此基础上利用空间杜宾模型分析其空间 溢出效应, 以期为指导中国农业绿色发展, 实现高质量增长提供参考。

\section{1 研究方法与数据来源}

\section{1 研究方法}

\subsection{1 非期望产出的 SBM 模型}

Tone 于 2001 年提出了基于非期望产出的 SBM 模型,能够有效解决径向和角度的传统 DEA 模型造成的 投人要素的“拥挤”或“松弛”现象。本文构建在规模报酬不变下的 SBM 模型测度中国农业环境效率,具体形 式如下 ${ }^{[21]}$ : 


$$
\begin{aligned}
& \rho^{*}=\min \frac{1-\frac{1}{N} \sum_{n=1}^{N} S_{n}^{x} / x_{k^{\prime} i}^{t^{\prime}}}{1+\frac{1}{M+1}\left(\sum_{m=1}^{M} s_{m}^{y} / y_{k^{\prime} m}^{t^{\prime}}+\sum_{i=1}^{I} s_{i}^{b} / b_{k^{\prime} i}^{t^{\prime}}\right)} \\
& \text { s.t. } \sum_{t=1}^{T} \sum_{k=1}^{K} z_{k}^{t} x_{k m}^{t}+s_{n}^{x}=x_{k^{\prime} n}^{t^{\prime}} \quad n=1,2, \cdots, N \\
& \sum_{t=1}^{T} \sum_{k=1}^{K} z_{k}^{t} x_{k m}^{t}-s_{m}^{y}=y_{k^{\prime} n}^{t^{\prime}} \quad m=1,2, \cdots, M \\
& \sum_{t=1}^{T} \sum_{k=1}^{K} z_{k}^{t} x_{k i}^{t}+s^{b}=x_{k^{\prime} n}^{t^{\prime}} \quad i=1,2, \cdots, I \\
& z_{k}^{t} \geqslant 0, s_{n}^{x} \geqslant 0, s_{m}^{y} \geqslant 0 \quad k=1,2, \cdots, K
\end{aligned}
$$

式中, $\rho^{*}$ 为农业环境效率值; $N 、 M 、 I$ 分别为投人、期望产出、非期望产出个数; $\left(s_{n}^{x}, s_{m}^{y}, s_{i}^{b}\right)$ 为投人产出的松弛 向量， $\left(x_{k^{\prime} n}^{t^{i}}, y_{k^{\prime} m}^{t^{\prime}}, b_{k^{\prime} i}^{t^{\prime}}\right)$ 是第 $k^{\prime}$ 地区在 $t^{\prime}$ 时期投人产出值; $z_{k}^{t}$ 表示决策单元权重; $\rho$ 取值范围为 $[0,1]$ 。

\subsection{2 空间马尔科夫链}

空间马尔科夫链 (Spatial markov chain) 在传统马尔科夫链中加人了空间滞后因素, 能够更好地刻画农业 环境效率在演变过程中与邻近省份的空间关联性 ${ }^{[22]}$ 。根据初始年份的空间滞后值将效率值划分为 $k$ 种类 型, 以省份 $i$ 在 $t$ 时期的空间滞后类型 $k$ 为条件, 进一步分成 $k$ 个 $k \times k$ 阶概率矩阵, 则从 $t$ 时期状态 $a$ 转移到 $t+$ 1 时期状态 $b$ 的概率为 $P_{a b / k}$, 公式如下:

$$
\operatorname{Lag}_{a}=\sum Y_{b} W_{i j}
$$

式中, $W_{i j}$ 表示邻近空间权重矩阵; $Y_{b}$ 表示省份 $b$ 的效率值; $\operatorname{Lag}_{a}$ 为省份 $a$ 的空间滞后值,表示省份 $a$ 的邻域 状态。

\subsection{3 空间自相关}

空间自相关能够考察农业环境效率是否存在空间相互关系,也是构建空间计量模型的必要条件。采用莫 兰指数 (Moran's I) 测度农业环境效率整体的空间关联特征,计算如下 ${ }^{[23]}$ :

$$
I=\frac{n \sum_{i=1}^{n} \sum W_{i j}\left|x_{i}-\bar{x}\right|\left|x_{j}-\bar{x}\right|}{\sum_{i=1}^{n} \sum_{j=1}^{n} W_{i j} \sum_{j=1}^{n}\left|x_{j}-\bar{x}\right|^{2}}
$$

式中, $x_{i}$ 和 $x_{j}$ 分别为 $i$ 省和 $j$ 省的农业环境效率; $\bar{x}$ 为平均值; $W_{i j}$ 为邻近空间权重矩阵。

\subsection{4 空间计量模型}

空间杜宾模型 (Spatial Durbin Model, SDM) 是分析空间溢出效应的主要模型,它是相较于空间误差模型 (Spatial Error Model, SEM) 和空间滞后模型 (Spatial Lag Model, SLM) 更为一般的形式 ${ }^{[24]}$,一般形式为:

$$
Y_{i t}=\beta X_{i t}+\rho \sum_{j=1}^{N} W_{i j} Y_{j t}+\varphi \sum_{j=1}^{N} W_{i j} X_{j t}+\mu_{i}+\nu_{t}+\varepsilon_{i t}
$$

式中, $Y_{i t} 、 X_{i t}$ 为第 $t$ 年区域 $i$ 的因变量和自变量的观测值; $W_{i j}$ 为空间权重矩阵; $\beta$ 为自变量的待估参数向量; $\rho$ 为因变量的空间滞后系数; $\varphi$ 为自变量的空间回归系数; $\mu_{i} 、 \nu_{t}$ 分别代表空间效应和时间效应; $\varepsilon_{i t}$ 为服从独立同 分布的随机误差项。综合已有研究 ${ }^{[17-20]}$, 选取财政支农、农业经济水平、工业化水平、农作物种植结构、环境 规制、农业生产能力和农业机械强度作为驱动因素变量 (表 1)。

1.2 指标体系构建与数据来源

本文基于以往研究农业环境效率的评价指标体系 ${ }^{[4-5,15-17]}$, 结合数据的可得性, 以投人产出理论为基础, 构建中国农业环境效率评价指标体系 (表 2)。 
表 1 农业环境效率影响指标变量与说明

Table 1 Variables and explanations of agricultural environmental efficiency influencing indicators

\begin{tabular}{lclc}
\hline $\begin{array}{l}\text { 驱动因素 } \\
\text { Driving factors }\end{array}$ & $\begin{array}{c}\text { 缩写 } \\
\text { Abbreviation }\end{array}$ & $\begin{array}{l}\text { 指标定义 } \\
\text { Definition }\end{array}$ & $\begin{array}{c}\text { 单位 } \\
\text { Unit }\end{array}$ \\
\hline 财政支农水平 Agriculture financial support & AFS & 农林水事务支出/地方财政一般预算支出 & $\%$ \\
农业经济水平 Agricultural economic degree & AED & 农村居民人均纯收人 & $\left(\times 10^{3}\right)$ 元/人 \\
工业化水平 Industrialization level & IND & 工业增加值/地区生产总值 & $\%$ \\
农作物种植结构 Crop planting structure & CPS & 粮食种植面积/除粮食外其他作物种植面积 & $\%$ \\
环境规制 Environmental regulation & $\mathrm{ENR}$ & 环境污染治理投资额/地区生产总值 & $\%$ \\
农业生产能力 Agricultural production capacity & $\mathrm{APC}$ & 农林牧渔业增加值/农业常住人口 & $\%$ \\
农业机械强度 Agricultural machinery strength & $\mathrm{AMS}$ & 农业机械总动力/农作物播种面积 & $\mathrm{kW} / \mathrm{hm}^{2}$ \\
\hline
\end{tabular}

表 2 中国农业环境效率指标体系

Table 2 Index system of agricultural environmental efficiency in China

\begin{tabular}{|c|c|c|c|}
\hline $\begin{array}{l}\text { 一级指标 } \\
\text { Primary index }\end{array}$ & $\begin{array}{l}\text { 二级指标 } \\
\text { Secondary index }\end{array}$ & $\begin{array}{l}\text { 指标说明 } \\
\text { Index description }\end{array}$ & $\begin{array}{l}\text { 单位 } \\
\text { Unit }\end{array}$ \\
\hline \multirow[t]{8}{*}{ 投入 Input } & 劳动投人 & 农业从业人员 & 万人 \\
\hline & 土地投人 & 农作物总播种面积 & $\mathrm{khm}^{2}$ \\
\hline & 用水投人 & 有效灌溉面积 & $\mathrm{khm}^{2}$ \\
\hline & 化肥投人 & 农用化肥施用量 & 万 $\mathrm{t}$ \\
\hline & 农药投人 & 农药使用量 & 万 $\mathrm{t}$ \\
\hline & 农膜投人 & 农膜使用量 & 万 $\mathrm{t}$ \\
\hline & 能源投入 & 农用柴油使用量 & 万 $\mathrm{t}$ \\
\hline & 机械投人 & 农业机械年末拥有量 & 万 $\mathrm{kW}$ \\
\hline 期望产出 Expected output & 农业产出 & 农业总产值 & 亿元 \\
\hline 非期望产出 & 农业碳排放量 & 化肥、农药、农膜、柴油、农业灌溉、农业翻耕碳排放量 & 万 $\mathrm{t}$ \\
\hline Unexpected output & $\mathrm{TN} 、 \mathrm{TP} 、 \mathrm{COD}$ 排放量 & $\begin{array}{l}\text { 农田化肥、畜禽养殖、水产养殖、农田秸秆等农业面源污 } \\
\text { 染的 TN、TP、COD 排放量 }\end{array}$ & 万 $\mathrm{t}$ \\
\hline
\end{tabular}

$\mathrm{TN}$ : 总氮 Total nitrogen; TP : 总磷 Total phosphorus; COD : 化学需氧量 Chemical oxygen demand

投人指标方面,选取劳动、土地、灌溉、化肥、农药、农膜、能源、机械等指标。期望产出指标方面,选取地区 农业总产值作为期望产出指标。非期望产出指标方面,选取了两类指标：(1)农业生产过程的碳排放，包括化 肥、农药、农膜、农用柴油、农业灌溉、农业翻耕所产生的碳排放。关于农业碳排放的计算,参考李波的方 法 ${ }^{[25]}$,将各排放源指标乘以排放系数,各系数为化肥 $0.896 \mathrm{~kg} / \mathrm{kg}$ 、农药 $4.934 \mathrm{~kg} / \mathrm{kg}$ 、农膜 $5.180 \mathrm{~kg} / \mathrm{kg}$ 、柴油 $0.593 \mathrm{~kg} / \mathrm{kg}$ 、农业灌溉 $20.476 \mathrm{~kg} / \mathrm{hm}^{2}$ 、农业耕作 $312.600 \mathrm{~kg} / \mathrm{hm}^{2}$ 。(2) 总氮 (TN)、总磷 (TP) 和化学需氧量 (COD) 等三类农业面源污染排放量, 根据农业生产中化肥、养殖和农作物固体废弃物所产生的污染物进行计 算,参考赖斯芸 ${ }^{[26]}$ 、段华平 ${ }^{[27]}$ 的研究, 选择农田化肥、畜禽养殖、水产养殖、农田秸秆四类农业面源污染的 $\mathrm{TN} 、 \mathrm{TP} 、 \mathrm{COD}$ 排放量。

本文尚缺中国香港、澳门、台湾、西藏自治区统计数据, 研究对象为中国 30 个省 (市、区), 相关数据主要 来源于《中国统计年鉴》、《中国农村统计年鉴》、《中国渔业统计年鉴》、《中国农业统计资料》以及各省份统计 年鉴, 部分缺失数据根据插值法进行推算补齐。

\section{2 农业环境效率的时空演变特征}

2.1 时间序列分析

根据公式 (1)SBM 模型,分别测算出 2004-2019 年考虑非期望产出和不考虑非期望产出两种情况下农 业环境效率值, 并绘制出变化趋势 (图 1)。由图 1 可知,在两种情况下中国农业环境效率均呈现出稳步上升 趋势, 但不考虑非期望产出的农业环境效率值整体上高于考虑非期望产出的效率值, 其中 2012 年的差值最 
大,2019 年差值最小,这说明了考虑非期望产出的农业环境效率值更符合实际生产情况, 评价结果相对更为 合理、科学。

可以发现,变异系数在 $0.302-0.563$ 之间变化, 区域差异整体上呈“上升-下降”的倒“V”型变化趋势。 2004-2011 年,变异系数经历了先小幅下降后加速上升的过程,整体呈上升的趋势特征,在 2007 年为最小值 0.302 , 表明此时区域差异较小,在 2011 为最大值 0.563 , 表明此时区域差异较大。2011-2019 年,变异系数波 动幅度较为轻微, 此时农业环境效率快速上升, 区域差异随着农业发展呈减小趋势, 逐步下降至 2019 年的 0.417。产生这种变化的原因可能是:2004-2011 年农业经济粗放式增长的负效应逐渐显现, 资源环境约束加 剧, 但其努力促进农业经济平稳较快发展, 因此农业环境效率整体呈上升趋势。2011-2019 年, 经济发展进 人新常态, 随着生态文明理念深人和政府对环境污染的治理力度加大, 致使这一时期农业环境效率增速较快, 随着区域协调发展的深人实施, 区域差异有所减小。

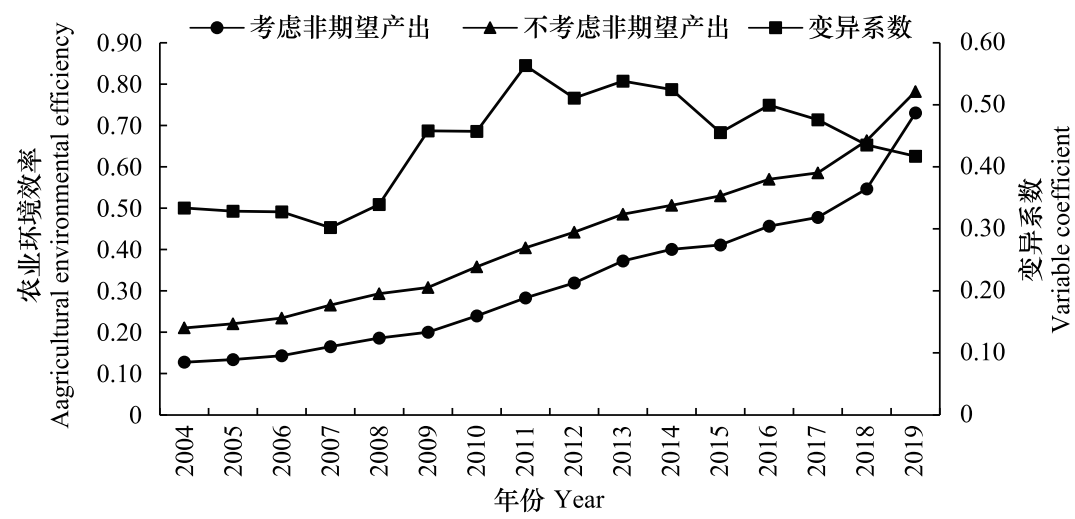

图 $12004-2019$ 年中国农业环境效率变化趋势

Fig.1 The trend of agricultural environmental efficiency in China from 2004 to 2019

进一步运用趋势面分析方法揭示研究期间中国农业环境效率空间趋势特征(图 2), Z 轴为农业环境效率 值。由图 2 可知, 东西方向上, 中国农业环境效率呈现出 “东高西低” 的趋势特征, 表现为一条从西到东上升
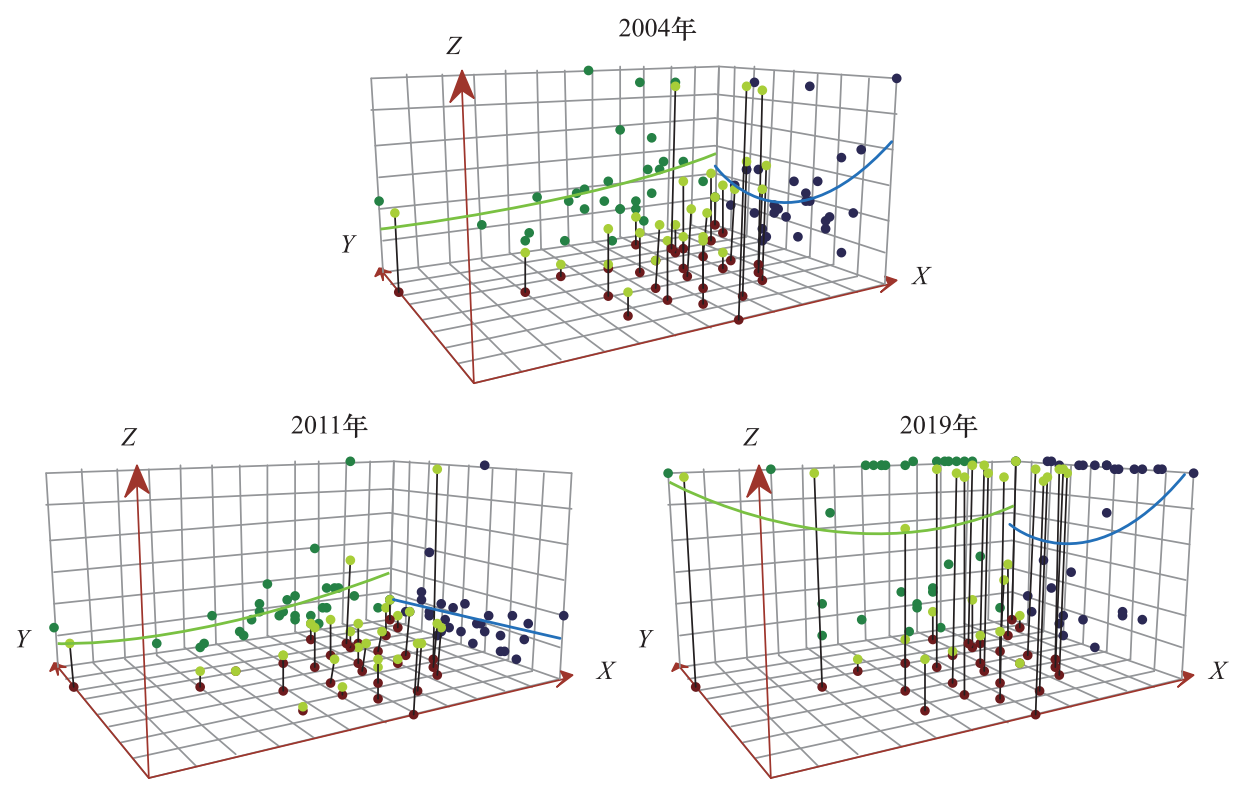

图 2 中国农业环境效率趋势面分析

Fig.2 The trend analysis of agricultural environmental efficiency in China 
的抛物线形状。南北方向上, 呈从北到南先下降后上升的态势, 逐渐表现为明显的 “中间低两端高” 的 “U” 型 趋势特征, 这充分表明 2004 年以来中国农业环境效率南方地区高于北方地区, 东部地区领先于西部地区。

2.2 空间分异特征

根据自然断点法将中国农业环境效率划分为低值、中低值、中高值、高值区进行可视化 (图 3)。由图 3 可 知, 中国不同等级的农业环境效率空间差异明显,高值区的省份占比逐渐增加, 低值区的省份占比逐渐下降。 具体而言,农业环境效率高值区范围显著增加, 当前主要分布在东部和西部个别省份, 新疆、青海、甘肃、贵州 这几个省份的经济实力不具有显著优势, 但从投人产出指标分析, 发现其劳动、土地等其他要素投人带来的农 业经济效应较高, 同时非期望产出较少。中高值区空间范围略有减少,其中东部的浙江、江苏、福建、广东逐步 从中高值跨人高值区。中低值和低值区空间范围持续减少, 主要分布在中部和西部地区, 集中分布在安徽、河 南、江西、湖南、内蒙古、陕西、宁夏、云南等省份, 这些省份有些是农业大省, 有些是连片山区, 由于劳动和其他 资源投人圥余, 资源利用率低, 经济产出效率不高, 并且污染物排放量增加,农业环境减排压力大, 导致农业环 境效率较低。
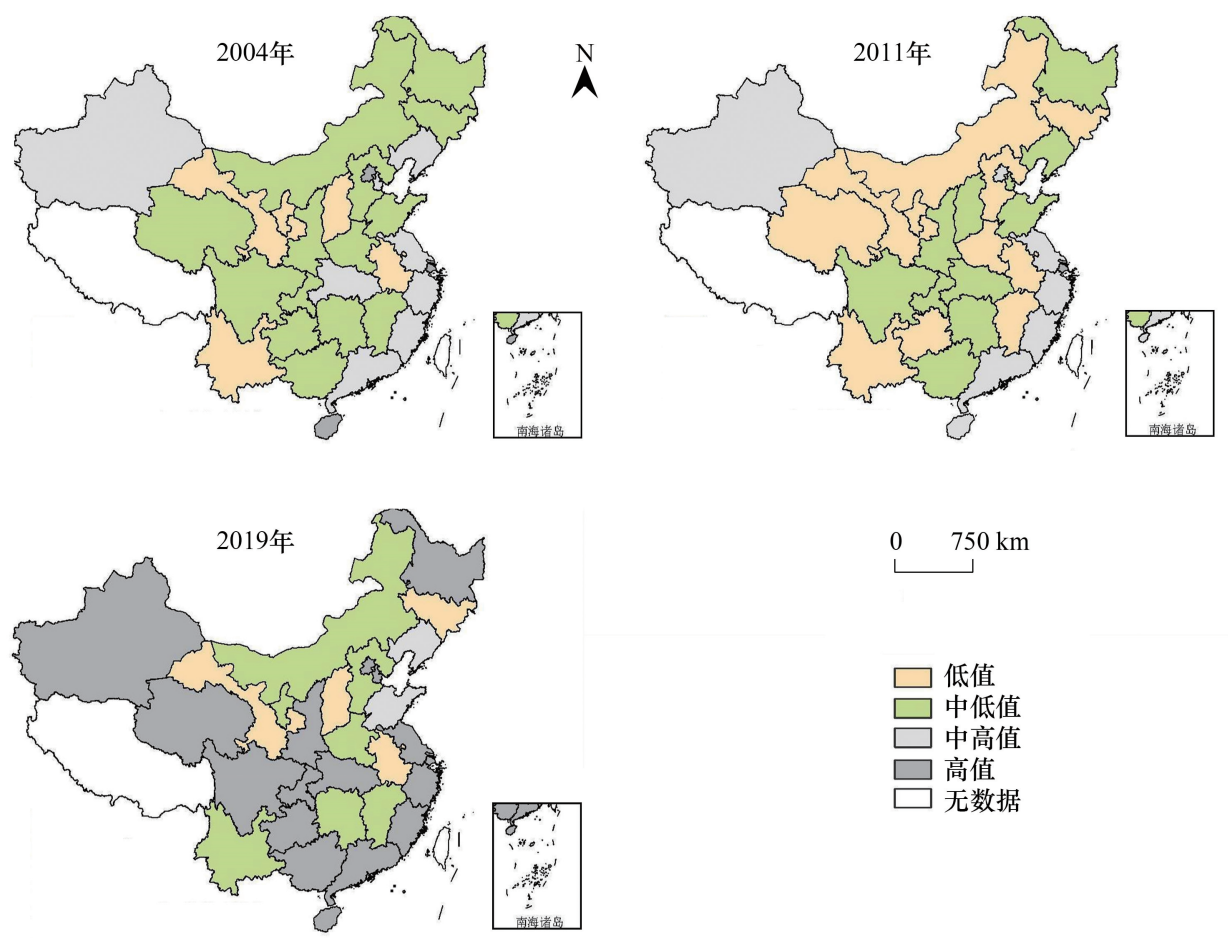

图 3 中国农业环境效率空间分布格局

Fig.3 The spatial pattern of agricultural environmental efficiency in China

2.3 空间演变特征

采用空间马尔科夫链分析中国农业环境效率的空间演化特征, 以初始年份的空间滞后值为分类基础,按 照四分位数的划分方法, 将农业环境效率值划分为 4 个相邻但不相互交叉的完备区间: (0.000, 0.159]、 $(0.159,0.246] 、(0.246,0.397]$ 及 $(0.397,1.000]$,并用 $k=1 、 2 、 3 、 4$ 分别来表示, 以此得到空间马尔科夫概率 转移矩阵 (表 3 )。

(1) 中国农业环境效率存在低效率、中低效率、中高效率和高效率 4 个趋同俱乐部特征。所有对角线上 的概率数字均远远大于非对角线上的数字, 这反映了农业环境效率不发生等级转移的概率要大于发生等级转 移的概率, 具有较强的稳定性。(2) 中国农业环境效率转移通常发生在相邻等级之间, 没有出现 “跳跃式” 转 移现象。例如在 2004-2011 年、2011-2019 年与 2004-2019 年, 低效率与中低效率向高效率转移的概率均 
为 $0.000\left(P_{14 / 1} 、 P_{24 / 1}\right)$, 这说明农业环境效率发展存在一定的“路径依赖” 性,较难实现“跨越式”发展。(3) 地 理空间格局在农业环境效率演变过程中具有重要作用。在与不同类型的省份相邻,转移的概率不同。例如, 在 2004-2019 年, 当自身为中高效率时,与低效率、中低效率省份相邻, 向上转移的概率分别为 $0.209\left(P_{34 / 1}\right)$ 、 $0.333\left(P_{34 / 2}\right)$, 向下转移的概率分别为 $0.791\left(P_{31 / 1}+P_{32 / 1}\right) 、 0.667\left(P_{31 / 2}+P_{32 / 2}\right)$ 。这表明农业环境效率发展与相 邻省份类型密切相关, 与效率较高省份为邻, 向上转移的概率增大, 反之, 向下转移的概率将增大。

表 3 农业环境效率的空间马尔可夫概率转移矩阵

Table 3 Spatial Markov probability transfer matrix of agricultural environmental efficiency

\begin{tabular}{|c|c|c|c|c|c|c|c|c|c|c|c|c|c|}
\hline \multirow{2}{*}{$\begin{array}{l}\text { 类型 } \\
\text { Type }\end{array}$} & \multirow{2}{*}{$t / t+1$} & \multicolumn{4}{|c|}{ 2004-2011 年 } & \multicolumn{4}{|c|}{2011 -2019 年 } & \multicolumn{4}{|c|}{ 2004-2019 年 } \\
\hline & & 1 & 2 & 3 & 4 & 1 & 2 & 3 & 4 & 1 & 2 & 3 & 4 \\
\hline \multirow[t]{4}{*}{1} & 1 & 0.783 & 0.217 & 0.000 & 0.000 & 0.000 & 0.000 & 0.000 & 0.000 & 0.783 & 0.217 & 0.000 & 0.000 \\
\hline & 2 & 0.009 & 0.724 & 0.267 & 0.000 & 0.000 & 0.000 & 0.000 & 0.000 & 0.009 & 0.724 & 0.267 & 0.000 \\
\hline & 3 & 0.000 & 0.009 & 0.782 & 0.209 & 0.000 & 0.000 & 0.000 & 0.000 & 0.000 & 0.009 & 0.782 & 0.209 \\
\hline & 4 & 0.000 & 0.011 & 0.000 & 0.989 & 0.000 & 0.000 & 0.000 & 0.000 & 0.000 & 0.011 & 0.000 & 0.989 \\
\hline \multirow[t]{4}{*}{2} & 1 & 0.000 & 0.000 & 0.000 & 0.000 & 0.000 & 1.000 & 0.000 & 0.000 & 0.000 & 0.000 & 0.000 & 0.000 \\
\hline & 2 & 0.000 & 0.750 & 0.250 & 0.000 & 0.000 & 0.560 & 0.440 & 0.000 & 0.000 & 0.750 & 0.250 & 0.000 \\
\hline & 3 & 0.000 & 0.000 & 0.667 & 0.333 & 0.000 & 0.016 & 0.774 & 0.210 & 0.000 & 0.000 & 0.667 & 0.333 \\
\hline & 4 & 0.000 & 0.000 & 0.000 & 1.000 & 0.000 & 0.021 & 0.000 & 0.979 & 0.000 & 0.000 & 0.000 & 1.000 \\
\hline \multirow[t]{4}{*}{3} & 1 & 0.000 & 0.000 & 0.000 & 0.000 & 0.333 & 0.667 & 0.000 & 0.000 & 0.000 & 0.000 & 0.000 & 0.000 \\
\hline & 2 & 0.000 & 0.000 & 0.000 & 0.000 & 0.000 & 0.696 & 0.304 & 0.000 & 0.000 & 0.000 & 0.000 & 0.000 \\
\hline & 3 & 0.000 & 0.000 & 0.000 & 0.000 & 0.000 & 0.000 & 0.780 & 0.220 & 0.000 & 0.000 & 0.000 & 0.000 \\
\hline & 4 & 0.000 & 0.000 & 0.000 & 0.000 & 0.000 & 0.000 & 0.000 & 1.000 & 0.000 & 0.000 & 0.000 & 0.000 \\
\hline \multirow[t]{4}{*}{4} & 1 & 0.000 & 0.000 & 0.000 & 0.000 & 0.000 & 0.000 & 0.000 & 0.000 & 0.000 & 0.000 & 0.000 & 0.000 \\
\hline & 2 & 0.000 & 0.000 & 0.000 & 0.000 & 0.000 & 0.000 & 0.000 & 0.000 & 0.000 & 0.000 & 0.000 & 0.000 \\
\hline & 3 & 0.000 & 0.000 & 0.000 & 0.000 & 0.000 & 0.000 & 0.333 & 0.667 & 0.000 & 0.000 & 0.000 & 0.000 \\
\hline & 4 & 0.000 & 0.000 & 0.000 & 0.000 & 0.000 & 0.000 & 0.000 & 1.000 & 0.000 & 0.000 & 0.000 & 0.000 \\
\hline
\end{tabular}

进一步绘制出各省份的空间演化格局 (图 4)。由图 4 可知,相邻省份的转移具有趋同特征,东部地区普 遍好于中西部地区。2004-2011 年,自身和邻域均向上转移的省份有 25 个; 自身向上、邻域不变的仅有 1 个 (青海) ; 自身不变、领域向上的有 3 个(甘肃、福建、海南); 自身和邻域均不变的有 1 个(宁夏)。2011-2019 年自身和邻域均向上转移的省份有 25 个; 自身向上、邻域不变的有 3 个 (甘肃、青海、宁夏); 自身不变、领域 向上的有 2 个(北京、广西)。2004-2019 年自身和邻域均向上的省份增加为 28 个; 自身向上、邻域不变和自 身不变、邻域向下的均有 1 个(青海和宁夏)。此外, 中国省份之间农业环境效率的关联作用是良好发展的, 均处于不变或向上状态,没有出现向下转移的倒退现象。

2.4 空间关联特征

通过 Moran's I 指数测度 2004一-2019 年中国农业环境效率的空间自相关程度 (表 4), 结果显示各年份的 全域 Moran's I 指数全部为正值, 且通过了显著性检验, 说明中国农业环境效率存在显著的正空间自相关性。

表 4 中国农业环境效率的莫兰指数

Table 4 Moran's $I$ index of agricultural environmental efficiency in China

\begin{tabular}{|c|c|c|c|c|c|c|c|c|}
\hline 年份 Year & 2004 & 2005 & 2006 & 2007 & 2008 & 2009 & 2010 & 2011 \\
\hline Moran'I & $0.292^{* * *}$ & $0.313^{* * *}$ & $0.363^{* * *}$ & $0.248^{* *}$ & $0.163^{*}$ & $0.130^{* *}$ & $0.118^{*}$ & $0.115^{* *}$ \\
\hline 年份 Year & 2012 & 2013 & 2014 & 2015 & 2016 & 2017 & 2018 & 2019 \\
\hline Moran'I & $0.098^{* *}$ & $0.025^{* *}$ & $0.016^{* * *}$ & $0.079^{* * *}$ & $0.049^{* * *}$ & $0.069^{* * *}$ & $0.094 * *$ & $0.104^{* *}$ \\
\hline
\end{tabular}



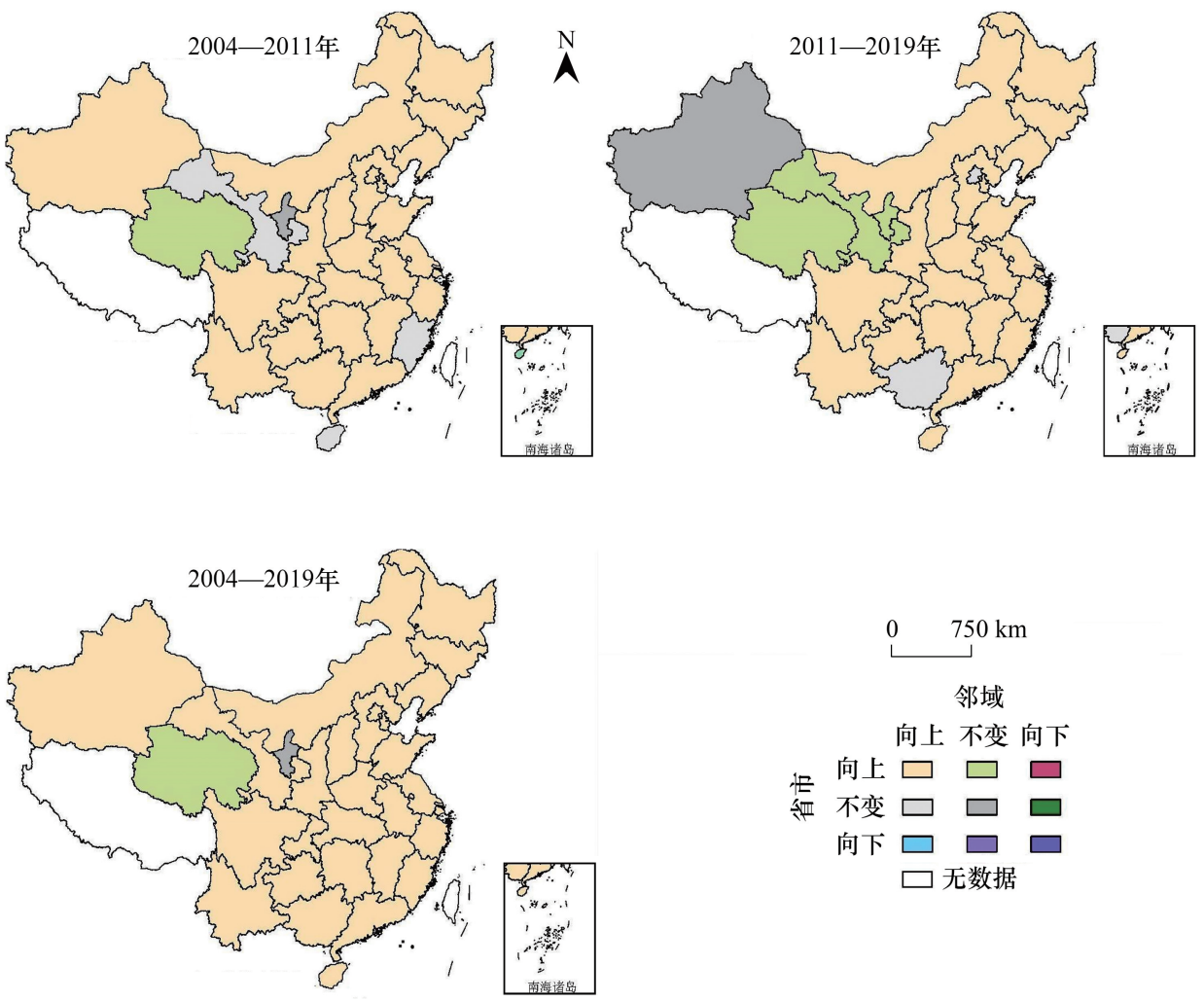

图 4 农业环境效率类型转变分布及邻域转变空间分布

Fig.4 Spatial of agriculture environmental type transformation and neighborhood transformation

\section{3 驱动因素分析}

\section{1 模型检验}

由表 5 可知,空间滞后模型的拉格朗日乘子 (Lagrange multipliers,LM) 检验未通过显著性检验,说明空间 误差模型优于空间滞后模型; 空间杜宾模型的沃尔德 (Wald) 和似然比 (Likelihood ratio, LR) 检验均通过了显 著性检验, 即拒绝可以简化的原假设, 表明空间杜宾模型不可简化为空间滞后模型或空间误差模型 ${ }^{[28-29]}$; 由 Hausman 统计量 75.729 且显著 $(P=0.000)$, 可以确定固定效应模型合适 ${ }^{[30]}$ 。

\section{表 5 空间计量模型选择检}

Table 5 Test selection of spatial econometric model

\begin{tabular}{|c|c|c|c|c|c|c|c|}
\hline $\begin{array}{c}\text { 空间滞后模型 } \\
\text { 的 LM 检验 } \\
\text { LM spatial } \\
\text { lag }\end{array}$ & $\begin{array}{c}\text { 稳健的空间滞 } \\
\text { 后模型的 } \\
\text { LM 检验 } \\
\text { Robust } \\
\text { LM-spatial lag }\end{array}$ & $\begin{array}{c}\text { 空间误差模型 } \\
\text { 的 LM 检验 } \\
\text { LM-spatial } \\
\text { error }\end{array}$ & $\begin{array}{c}\text { 稳健的空间误 } \\
\text { 差模型的 } \\
\text { LM 检验 } \\
\text { Robust } \\
\text { LM-spatial error }\end{array}$ & $\begin{array}{c}\text { 空间滞后模型 } \\
\text { 的 Wald 检验 } \\
\text { Wald-spatial } \\
\text { lag }\end{array}$ & $\begin{array}{c}\text { 空间滞后模型 } \\
\text { 的 LR 检验 } \\
\text { LR-spatial } \\
\text { lag }\end{array}$ & $\begin{array}{c}\text { 空间误差模型 } \\
\text { 的 Wald 检验 } \\
\text { Wald-spatial } \\
\text { error }\end{array}$ & $\begin{array}{c}\text { 空间误差模型 } \\
\text { 的 LR 检验 } \\
\text { LR-spatial } \\
\text { error }\end{array}$ \\
\hline $\begin{array}{c}0.051 \\
(0.882)\end{array}$ & $\begin{array}{c}16.343 \\
(0.001)\end{array}$ & $\begin{array}{c}7.370 \\
(0.007)\end{array}$ & $\begin{array}{c}23.662 \\
(0.000)\end{array}$ & $\begin{array}{c}24.814 \\
(0.000)\end{array}$ & $\begin{array}{c}24.272 \\
(0.001)\end{array}$ & $\begin{array}{c}25.171 \\
(0.000)\end{array}$ & $\begin{array}{c}24.273 \\
(0.001)\end{array}$ \\
\hline
\end{tabular}

LM:拉格朗日乘子 Lagrange multipliers, LR: 似然比 Likelihood ratio; 括号内为 $P$ 值

\section{2 结果分析}

根据表 6 ,对比自然对数似然值 (Log-likelihood) 和拟合优度 $\left(R^{2}\right)$ 可知, 固定效应模型的拟合效果较好。 空间自相关系数 $\rho$ 的估计值为 0.160 , 且通过了 $5 \%$ 显著性水平检验, 表明了农业环境效率存在显著的空间溢 出效应。各变量系数显示, 财政支农水平对农业环境效率产生显著的负向影响, 原因可能是虽然财政支农能 
够增加农民收人水平,但是当前财政支农的结构不合理, 大部分花费在对农药、化肥和农机的补贴上,加重了 农业污染物的排放, 反而不利于农业环境效率提升。农业经济发展水平的弹性系数为正, 表明农民收人的增 加有助于农业环境效率的提升。工业化水平产生显著的负向影响,原因是工业化水平的提升为农业生产提供 了机械、技术支持, 但随着工业化发展, 加重了石油农业的程度,农业非期望产出增加, 对农业环境效率产生了 较强的负向效应。农作物种植结构的系数显著为负, 原因主要是经济作物通常具有地域性强、水肥需求高、自 然条件要求较严格等特点,其种植面积的扩大将导致化肥投人的增长和面源污染的加重,这些因素不利于农 业环境效率的提升。环境规制和农业生产能力具有显著的正向影响, 说明环境规制强度和农业生产能力的提 升能够对农业环境效率产生积极影响。农业机械强度具有显著的负向影响,虽然农业机械使用强度的提升能 够提高劳动生产率, 但当前更侧重于农业机械化生产, 忽视了经济、资源与环境的协调发展, 环境负效应超过 了正效应,因此对农业环境效率产生负向作用。

表 6 空间杜宾模型估计结果

Table 6 The estimation results of spatial Durbin model

\begin{tabular}{|c|c|c|c|c|c|c|c|c|c|}
\hline \multirow{2}{*}{$\begin{array}{c}\begin{array}{c}\text { 变量 } \\
\text { Variable }\end{array} \\
\text { AFS }\end{array}$} & \multicolumn{2}{|c|}{$\begin{array}{c}\text { 随机效应 } \\
\text { Random effect }\end{array}$} & \multicolumn{2}{|c|}{$\begin{array}{l}\text { 固定效应 } \\
\text { Fixed effect }\end{array}$} & \multirow{2}{*}{$\begin{array}{c}\begin{array}{c}\text { 变量滞后项 } \\
\text { Spatial lag }\end{array} \\
\text { W×AFS }\end{array}$} & \multicolumn{2}{|c|}{$\begin{array}{c}\text { 随机效应 } \\
\text { Random effect }\end{array}$} & \multicolumn{2}{|c|}{$\begin{array}{l}\text { 固定效应 } \\
\text { Fixed effect }\end{array}$} \\
\hline & $-0.006^{* *}$ & $(-2.028)$ & $-0.006^{* *}$ & $(-2.183)$ & & $0.011^{* * *}$ & $(1.922)$ & $0.015^{\text {*** }}$ & $(2.583)$ \\
\hline AED & $0.033^{* *}$ & $(8.025)$ & $0.034^{* * *}$ & $(7.881)$ & $\mathrm{W} \times \mathrm{AED}$ & -0.001 & $(-0.094)$ & $0.012^{* *}$ & $(2.445)$ \\
\hline IND & $-0.537^{* * *}$ & $(-4.916)$ & $-0.682^{* * *}$ & $(-5.637)$ & $\mathrm{W} \times \mathrm{IND}$ & -0.237 & $(-0.959)$ & $-0.497^{*}$ & $(-1.939)$ \\
\hline CPS & $-0.463 * * *$ & $(-3.797)$ & $-0.895^{* * *}$ & $(-6.123)$ & $\mathrm{W} \times \mathrm{CPS}$ & -0.081 & $(-0.401)$ & $-0.600^{* *}$ & $(-2.062)$ \\
\hline ENR & $0.019^{* *}$ & $(2.095)$ & $0.023^{* * *}$ & $(2.589)$ & $\mathrm{W} \times \mathrm{ENR}$ & $-0.037^{* *}$ & $(-1.977)$ & $-0.031^{*}$ & $(-1.744)$ \\
\hline APC & $0.021^{* * *}$ & $(8.920)$ & $0.023^{* * *}$ & $(9.131)$ & $\mathrm{W} \times \mathrm{APC}$ & $-0.011^{* *}$ & $(-1.964)$ & $-0.013^{* *}$ & $(-2.155)$ \\
\hline AMS & $-0.012^{* * *}$ & $(-2.620)$ & $-0.017^{* * *}$ & $(-2.972)$ & W $\times$ AMS & 0.011 & $(1.334)$ & 0.006 & $(0.535)$ \\
\hline$R^{2}$ & \multicolumn{2}{|c|}{0.698} & \multicolumn{2}{|c|}{0.863} & $\rho$ & $0.107^{*}$ & (1.661) & $0.160^{* *}$ & $(2.464)$ \\
\hline $\begin{array}{c}\text { 自然对数似然值 } \\
\text { Log-likelihood }\end{array}$ & \multicolumn{2}{|c|}{418.735} & \multicolumn{2}{|c|}{483.867} & & & & & \\
\hline
\end{tabular}

$* * *$ 、** 和 $*$ 分别表示在 $1 \% 、 5 \%$ 和 $10 \%$ 水平下显著; $\rho$ 为空间滞后示数; 括号内数值为 $t$ 统计量的值

\section{3 效应分解}

利用 SDM 模型将总效应分解为直接效应和间接效应(表 7)。直接效应中各变量回归系数在影响方向和 显著性上与表 6 中结果具有一致性。在间接效应方面,财政支农水平的系数显著为 0.014 ,财政支农水平每提 高 1 单位,邻近省份农业环境效率会提升 0.014 个单位, 表明财政支农水平对邻近省份农业环境效率具有促 进作用。环境规制的系数显著为 -0.032 , 虽然环境规制对本省份农业环境效率具有积极作用,但不利于邻近 省份发展,环境规制强度每提升 1 单位,会导致邻近省份农业环境效率下降 0.032 个单位。农业生产能力的 系数显著为 -0.015 , 表明农业生产能力对邻近省份农业环境效率具有负向影响, 并且农业生产能力平均提高 1 单位, 邻近省份农业环境效率平均下降 0.015 个单位。除此之外,农业经济水平、工业化水平、农作物种植结 构和农业机械强度具有显著的直接效应,但空间溢出效应不显著。

表 7 空间杜宾模型的直接和间接效应

Table 7 The direct effect and indirect effect of spatial durbin model

\begin{tabular}{|c|c|c|c|c|c|c|}
\hline \multirow{2}{*}{$\frac{\text { 变量 Variable }}{\text { AFS }}$} & \multicolumn{2}{|c|}{ 直接效应 Direct effect } & \multicolumn{2}{|c|}{ 间接效应 Indirect effect } & \multicolumn{2}{|c|}{ 总效应 Total effect } \\
\hline & $-0.007^{* *}$ & $(-2.228)$ & $0.014^{* * *}$ & $(2.768)$ & 0.007 & $(1.409)$ \\
\hline AED & $0.034^{* * * *}$ & $(7.485)$ & 0.006 & $(0.889)$ & $0.040^{* * * *}$ & $(7.570)$ \\
\hline IND & $-0.672^{* * * *}$ & $(-5.465)$ & -0.351 & $(-1.582)$ & $-1.023^{* * *}$ & $(-4.410)$ \\
\hline CPS & $-0.878^{* * *}$ & $(-6.128)$ & -0.422 & $(-1.625$ & $-1.300^{* * *}$ & $(-5.458)$ \\
\hline ENR & $0.025^{* * * *}$ & (1.828) & $-0.032 *$ & $(-1.944)$ & -0.007 & $(-0.403)$ \\
\hline APC & $0.024^{* * *}$ & $(9.408)$ & $-0.015^{* * *}$ & $(-2.868)$ & 0.009 & $(1.525)$ \\
\hline AMS & $-0.018^{* * *}$ & $(-3.131)$ & 0.008 & $(0.730)$ & -0.009 & $(-0.736)$ \\
\hline
\end{tabular}

$* * *$ 、**和 $*$ 分别表示在 $1 \% 、 5 \%$ 和 $10 \%$ 水平下显著; 括号内数值为 $t$ 统计量的值 


\section{4 结论与讨论}

\section{1 结论}

本文运用考虑非期望产出的 SBM 模型测度出 2004-2019 年中国 30 个省(市、区)农业环境效率,并利用 空间马尔科夫链、空间杜宾模型等方法探究中国农业环境效率的时空演变特征及其驱动因素,得到以下主要 结论:

(1) 中国农业环境效率在不考虑非期望产出下明显高于考虑非期望产出的农业环境效率值,考虑期望产 出值更符合实际的农业生产过程,呈稳步上升趋势; 区域间差异明显,整体呈倒“V”型变化趋势,并在东西方 向上低阶梯递减,南北方向上呈“U”型趋势特征。

(2) 中国不同等级的农业环境效率空间差异明显, 高值区范围显著增加, 中高值区空间范围略有减少, 中 低值和低值区空间范围持续减少; 中国农业环境效率存在俱乐部趋同现象,具有空间溢出效应,且溢出效应呈 现时空异质性,地理空间关联性在空间演变过程具有重要作用,当前农业环境效率处在良好发展阶段,均没有 出现向下转移的倒退现象。

(3) 驱动因素显示,财政支农水平、环境规制、农业生产能力同时具有直接效应与间接效应,财政支农水 平对本省份的直接影响显著为负，但对邻近省份具有显著促进作用; 环境规制、农业生产能力对本省份影响显 著为正, 但对邻近省份影响为负。农业经济水平、工业化水平、农作物种植结构、农业机械强度则只具有直接 效应而间接效应不显著,其中,农业经济水平具有正向作用,工业化水平、农作物种植结构、农业机械强度产生 显著负向影响。

4.2 讨论

根据研究结论,为提高中国农业环境效率,促进农业绿色发展,提出以下建议:

(1) 从效率值大小看,农业环境效率处于非有效状态。2004-2019 年中国 30 个省份的农业环境效率均 值处在 0.128一 0.730 之间,当前农业生产仍存在高投人、低效率的粗放型发展方式,且存在区域不平衡现象， 具有东高西低、南高北低现状。因此,农业环境效率较高的东部地区省份可以通过提高资源利用效率,促进农 业先进技术使用,增加农业总产值,减少污染排放。中部地区的省份需要适当调整资源要素的投人比例,通过 劳动力、土地、用水及化肥等资源的使用规模和结构的优化配置,实现资源集约利用,向绿色生产转变。西部 地区尤其是内蒙古、甘肃、宁夏等省份对资源的依赖性较高, 首先要转变农业生产和资源利用观念, 将生态农 业纳人到农业考核体系中,促进农业生产的经济效益与生态环境协调发展。

(2)中国农业环境效率存在正向空间溢出效应,因此要加强各级政府间的合作,跨越行政区划限制,打破 区域壁垒,促进各类要素自由流动,加强在资源环境领域方面的交流与合作。农业环境效率高的东部地区省 份要继续发挥在科研和技术创新方面的引领作用,积极向效率低的省份传播先进技术和生产经验; 环境效率 较低的中西部地区省份则要积极利用东部地区的先进技术和创新成果, 改进农业生产技术,在保护环境的同 时对资源合理使用,减少致污性生产源的投人。通过区域、省份之间的有效合作,使农业环境效率较高的省份 辐射带动邻近省份, 促进整体效率提升。

(3) 驱动因素显示,农业经济水平、环境规制、农业生产能力是提升农业环境效率的关键因素,财政支农 水平、工业化水平、农作物种植结构、农业机械强度则是制约效率提升的约束要素。因此,各省份在追求农业 经济增长的同时,要充分认识发展差异,探索适宜的农业绿色发展道路,合理分配财政支农结构,尤其提高环 保型农资补贴,强调由政策支持为主转向重视农业自身发展着手,结合自身优势要素,积极引进先进生产技术 和管理经验,加强生态技术开发与推广,引导农业向生态化的方向发展,此外,要增强对境污染治理的态度,注 重环境规制对农业环境效率的驱动作用。

\section{参考文献 (References) :}

[ 1 ] 杜江, 王锐, 王新华. 环境全要素生产率与农业增长: 基于 DEA-GML 指数与面板 Tobit 模型的两阶段分析. 中国农村经济, 2016(3)： 
65-81.

[ 2 ] Schaltegger S, Sturm A. Okologische rationalitat: ansatzpunkte zur ausgestaltung yon okologieorient management instrument. Die Unternehmung, 1990, 4: 273-290.

[ 3 ] Verfaillie H A, Bidwell R, Cowe R. Measuring eco-efficiency: a guide to reporting company performance. World Business Council for Sustainable Development, 2000.

［4］姚增福. 环境规制、农业投资与农业环境效率趋同——“波特假说”和投资调整成本整合框架的分析. 统计研究, 2020，37(8)：50-63.

[ 5 ] 张子龙, 鹿晨昱, 陈兴鹏, 薛冰. 陇东黄土高原农业生态效率的时空演变分析一一以庆阳市为例. 地理科学, 2014, 34(4): 472-478.

[ 6 ] 王海飞. 基于 SSBM-ESDA 模型的安徽省县域农业效率时空演变. 经济地理, 2020, 40(4) : 175-183+222.

[ 7 ] 姚增福, 唐华俊, 刘欣. 规模经营行为、外部性和农业环境效率——基于西部两省 770 户微观数据的实证检验. 财经科学, 2017(12)： 69-83.

[ 8 ] 刘魏, 张应良, 李国珍, 田红宇. 工商资本下乡、要素配置与农业生产效率. 农业技术经济, 2018(9): 4-19.

[9] 魏琦, 张斌, 金书秦. 中国农业绿色发展指数构建及区域比较研究. 农业经济问题, 2018(11): 11-20.

[10] Ma W J, Meng L H, Wei F L, Opp C, Yang D W. Spatiotemporal variations of agricultural water footprint and socioeconomic matching evaluation from the perspective of ecological function zone. Agricultural Water Management, 2021, 249(30) : 1-11.

[11] Zhou Y H, Zhang X H, Tian X, Geng X H, Zhang P, Yan B J. Technical and environmental efficiency of hog production in China: A stochastic frontier production function analysis. Journal of Integrative Agriculture, 2015, 14(6) : 1069-1080.

[12] Coluccia B, Valente D, Fusco G, De Leo F, Porrini D. Assessing agricultural eco-efficiency in Italian Regions. Ecological Indicators, 2020, 116: 1-12.

[13] Moutinho V, Robaina M, Macedo P. Economic-environmental efficiency of European agriculture - a generalized maximum entropy approach. Agricultural Economics, 2018, 64(10): 423-435.

[14] 姚增福, 刘欣. 要素禀赋结构升级、异质性人力资本与农业环境效率. 人口与经济, 2018(2) : 37-47.

[15] Qi X X, Fu Y H, Wang R Y, Ng C N, Dang H P, He Y L. Improving the sustainability of agricultural land use: An integrated framework for the conflict between food security and environmental deterioration. Applied Geography, 2018, 90 : 214-223.

[16] 胡平波, 钟渏萍. 政府支持下的农旅融合促进农业生态效率提升机理与实证分析一一全国休闲农业与乡村旅游示范县为例. 中国农村 经济, 2019, (12): 85-104.

[17] 王圣云, 林玉娟. 中国区域农业生态效率空间演化及其驱动因素一一水足迹与灰水足迹视角. 地理科学, 2021, 42(2): 290-301.

[18］侯孟阳，姚顺波. 中国农村劳动力转移对农业生态效率影响的空间溢出效应与门槛特征. 资源科学, 2018, 40(12)：2475-2486.

［19］吴梵，高强，刘韬. 农业科技创新、空间溢出与农业生态效率. 统计与决策，2020，36(16)：82-85.

[20］李博, 张文忠, 余建辉. 碳排放约束下的中国农业生产效率地区差异分解与影响因素. 经济地理, 2016, 36(9): 150-157.

[21] Tone K. A slacks-based measure of efficiency in data envelopment analysis. European Journal of Operational Research, 2001, 130(3) : 498-509.

[22] 郭艳花, 佟连军, 梅林. 吉林省限制开发生态区绿色发展水平评价与障碍因素. 生态学报, 2020, 40(7)：2463-2472.

[23] 赵良仕, 孙才志, 郑德风. 中国省际水足迹强度收玫的空间计量分析. 生态学报, 2014, 34(5): 1085-1093.

[24] 关伟, 许淑婷. 中国能源生态效率的空间格局与空间效应. 地理学报, 2015，70(6)：980-992.

[25] 李波, 张俊㨢, 李海鹏. 中国农业碳排放时空特征及影响因素分解. 中国人口・资源与环境, 2011, 21(8): 80-86.

[26] 赖斯芸. 非点源调查评估方法及其应用研究 [D]. 北京: 清华大学, 2003.

[27］段华平. 农业非点源污染控制区划方法及其应用研究[D]. 南京: 南京农业大学, 2010.

[28] Elhorst J P. Specification and estimation of spatial panel data models. International Regional Science Review, 2003, 26(3) : 244-268.

[29] LeSage J, Pace R K. Introduction to Spatial Econometrics. New York: CRC Press, 2009.

[30］李兆亮, 罗小锋, 张俊遥, 丘雯文. 农业 R\&D 投人、空间溢出与中国农业经济增长. 科研管理, 2020, 41(9): 268-277. 